\title{
O MOVIMENTO PERONISTA COMO "LUGAR DE MEMÓRIA" DA AMÉRICA LATINA: UM OLHAR DA HISTÓRIA E DA LITERATURA
}

\author{
THE PERONIST MOVEMENT AS "PLACE OF MEMORY" IN LATIN
}

AMERICA: A VIEW FROM HISTORY AND LITERATURE

Enviado em 12 de março de 2015

Aceito em 26 de abril de 2015

Raquel Paz dos Santos ${ }^{1}$

Maria Auxiliadora Fontana Baseio ${ }^{2}$

\begin{abstract}
Resumo: O presente estudo analisa a problemática dos lugares de memória na construção do imaginário social do peronismo entre 1946-1955, destacando a criação de mitos e "mártires" em torno de Perón e Evita, símbolos e comemorações cívicas que recriaram simbolicamente a nação, alimentando o projeto da "Nova Argentina". Demonstra-se, ainda, que, pelo estabelecimento de políticas sociais para os trabalhadores, associado a uma intensa propaganda ideológica produzida pelo controle da imprensa e da repressão e desmoralização dos grupos opositores, legitimou-se o poder instituído. Essa construção simbólica que compôs o imaginário social da época, constituindo-se como um discurso dominante, foi profundamente criticada pela intelectualidade argentina, sobretudo por alguns escritores, que encontraram na literatura um meio de expressão de suas representações contrárias ao regime - um contradiscurso -, buscando, assim, estratégias de romper com o silenciamento e promover o embate simbólico entre as diferentes visões, como se analisa no conto "A casa tomada", de Cortázar.
\end{abstract}

Palavras-chave: Lugares de memória. Peronismo. História. Literatura.

Abstract: This study discusses "places of memory" in the construction of the social imaginary of Peronism in Argentina between 1946 and 1955, highlighting the creation of myths and "martyrs" surrounding the personalities of Perón and

\footnotetext{
1 Graduação em História pela Universidade do Estado do Rio de Janeiro (UERJ) e mestrado em Memória Social pela Universidade Federal do Estado do Rio de Janeiro (UNIRIO).Doutora em História pela Universidade Federal Fluminense (UFF). Pós-Doutora em História pela Universidade Federal do Rio de Janeiro (UFRJ). Professora do Mestrado Interdisciplinar em Ciências Humanas pela Universidade de Santo Amaro - SP. E-mail: raquelpazdossantos@terra.com.br

2 Graduação em Graduação em Português e Inglês pelo Centro Universitário Ibero Americano (UNIBERO) e em Ciências Sociais pela Universidade de São Paulo (USP). Mestre em Letras e Doutora em Estudos Comparados de Literaturas de Língua Portuguesa pela Universidade de São Paulo (USP). Professora do Mestrado Interdisciplinar em Ciências Humanas pela Universidade de Santo Amaro - SP.
} 
Evita. Also examined are the symbols and civic events that were employed to represent Perón's "New Argentina". This article also shows that the establishment of social policies for workers, combined with intense ideological propaganda, control of the press, as well as repression and demoralization of opposition groups, legitimized Perón's power. Perón's symbolic construction that fed the social imaginary of the time constituted itself as the dominant discourse. This discourse was deeply criticized by Argentine intellectuals, especially by writers, who found in literature a means of expression of representations that ran counter to the regime. In this way, those writers searched for strategies to break their silence and promote the symbolic conflict between the differing visions, as we analyze in the story " $A$ casa tomada", by Cortázar.

Keywords: Place of memory. Peronism. History. Literature.

\section{INTRODUÇÃO}

As reflexões acerca da memória constituem, hoje, temática e problemática não apenas do campo da História, mas também de outras Ciências Humanas. Vários foram os estudiosos que se debruçaram, em todos os tempos, no intuito de compreender o tema nas diferentes sociedades. No século XXI, em que se mostram ameaças de uma perda de memória, ou de uma "amnésia coletiva", no dizer de Le Goff (2003, p. 466), o tema ganha ainda mais força.

No tecer do cenário da mundialização, Pierre Nora assinala: "Há locais de memória porque não há mais meios de memória" (NORA, 1981, p. 7). A busca por lugares de memória explica-se por seu esfacelamento e substituição: da memória perene à memória efêmera e consequente esquecimento. E acrescenta o autor: "se habitássemos ainda nossa memória, não teríamos necessidade de lhe consagrar lugares "(NORA, 1981, p. 8), "a memória pendura-se em lugares, como a história em acontecimentos" (NORA, 1981, p. 25). A partir dessas premissas, assinalamos nossa busca pela compreensão de uma memória significativa para a América Latina: o peronismo.

Segundo Federico Neiburg (1998, p. 14), compreender o peronismo é fundamental para se entender a Argentina contemporânea, trata-se, ainda, de uma das mais tradicionais culturas políticas latino-americanas. Desta forma, nosso estudo pretende analisar os principais aspectos da construção da memória do peronismo a partir das políticas culturais desenvolvidas pelo Estado argentino entre 1946 a 1955, visando forjar representações simbólicas que legitimassem seu poder e buscando 
abolir do imaginário social toda a representação da coletividade que ameaçasse a ordem vigente mediante mecanismos de censura. Neste contexto, analisaremos, também, uma perspectiva que revela a contra-memória do regime criada por Cortázar na obra A Casa Tomada. Cortázar foi intelectual argentino antiperonista e crítico a essas práticas autoritárias. Dentro deste universo simbólico com forte conotação política, refletiremos sobre a concepção "lugares de memória" proposta por Pierre Nora.

\section{O PROJETO DA “NOVA ARGENTINA” NO IMAGINÁRIO PERONISTA}

As recordações do povo argentino sobre o general Juan Domingo Perón remetem ao golpe de Estado de 4 de julho de 1943. Como um dos seus principais idealizadores, tornou-se figura política de destaque, passando a acumular cargos de vice-presidente, Ministro da Guerra e da Secretaria de Trabalho e Previdência Social. No exercício dessa secretaria, adotou uma série de medidas ${ }^{3}$ em benefício da classe trabalhadora, conquistando seu apoio a ponto de organizar um movimento sindical centrado em sua figura.

Em 1945, Perón foi afastado do governo por pressões das classes dominantes, contrárias à sua política trabalhista. Em 17 de outubro deste mesmo ano, uma grande manifestação de trabalhadores na Plaza de Mayo, que exigiu a liberdade de Perón, marcou o início do que, durante várias décadas, foi denominado de peronismo. Estudiosos argentinos, como Neiburg, definem esse acontecimento como "mito de origem do peronismo" ou como "acontecimento mito", no dizer de Aberto Ciria (1983, p. 15).

O 17 de outubro, caracterizado como "Día de la Lealdad", foi adotado como comemoração do regime, passando a constituir um ritual que reconstruía simbolicamente a comunicação entre Perón e o povo, recriando e reforçando ainda mais sua imagem carismática. Assim, esse evento figurou como lugar de memória marcante do regime.

Outro aspecto importante dessa mobilização foi a apropriação pelos peronistas dos símbolos da pátria, como o Hino Nacional e a bandeira, que se tornaram rituais. As marchas aconteciam ao redor dos monumentos aos heróis nacionais, especialmente San Martín. Por isso, os manifestantes de outubro denominavam-se como o "verdadeiro povo", reais representantes da nacionalidade argentina. Os setores que se

\footnotetext{
${ }^{3}$ Elevação dos níveis salariais, obrigatoriedade do cumprimento das leis existentes, além da elaboração de novas leis como o pagamento de férias e do Aguinaldo (13ํaário), criação de novos sindicatos, entre outros.
} 
negavam a colaborar com o projeto governamental eram excluídos, sendo definidos como "antipatrióticos" ou "inimigos públicos".

O 24 de fevereiro de 1946, quando Perón foi eleito presidente, demarca outro fato importante da fundação dessa tradição política. Assim, as comemorações em torno dessas três datas assinalaram as etapas da ação revolucionária e tornaram-se imagéticas simbólicas da memória coletiva: primeiro, as Forças Armadas atendem ao clamor do povo, logo após o apoio popular por ocasião da queda de Perón e, finalmente, deste apoio foi reafirmado com sua vitória nas eleições.

O "Día de La Lealdad" foi apontado como o início da história da "Nova Argentina"; o passado, sua pré-história. Nesse aspecto, destaca-se uma característica importante das políticas estatais que, apesar de reprovarem os valores originários da Revolução Francesa, apropriaram-se das imagens criadas por ela. Foi exaltado o "mito da Revolução" e o iniciar triunfante de um novo tempo, o "esquecimento" do que ocorreu no passado definido como tempo da injustiça, da "degradação da nação" e todo o complexo e profundo processo pedagógico de formação de indivíduos em consonância com os ideais peronistas.

Neste sentido, Mariano Plotkin (1995, p. 208-209) ressalta que, no início de 1948, Oscar Ivanissevich, ao assumir a direção da Secretaria de Educação, procurou fazer a ligação da ideologia do regime com a religião católica. As reformas realizadas no sistema educacional, incluídas nos currículos escolares, com a finalidade de divulgar a ideologia dominante através de revistas, livros e textos de leitura foram importante contribuição para a legitimação simbólica do regime. Por meio da educação, Perón procurou superar a luta de classes, unindo todos os argentinos em um só desejo, valorizando as tradições e a história do país. Essas diretrizes educacionais foram fundamentais para a formação de uma identidade coletiva.

Segundo as análises de Maurice Halbwachs, a memória coletiva "se baseia na identidade e legitimidade de um grupo, na lembrança da histórica, organizando-se em torno de um evento fundador que absorve os antecedentes e os posteriores" (HALBWACHS,1990, p.39). Nesse sentido, compreendemos como o governo peronista fundou uma memória com a qual se identificaram diversos setores da sociedade, jogando para o esquecimento os acontecimentos anteriores e posteriores ao regime, pois estavam dissociados de uma existência coletiva.

O presidente também era representado como o "pai dos trabalhadores", o "pai dos descamisados", o "primeiro trabalhador". Além de ser identificado com os heróis nacionais, ligados ao movimento de independência, como San Martin e Rosas, no passado como no presente, o "condutor das massas" procurava promover a liberdade da pátria. 


\section{Rounts

Sua esposa, Eva Perón, foi exaltada como a "mãe dos descamisados". Sua figura representava a mulher que se sacrificou pelos "filhos da pátria" até sua morte, sendo considerada e idolatrada como "Chefe Espiritual da Nação". Após seu falecimento em 1952, construiu-se no imaginário coletivo a representação da primeira dama como uma "santa", devido à crença de sua total dedicação à causa dos humildes, com a renúncia da própria vida. Essa imagem foi muito explorada pela propaganda ideológica do regime, procurando manter viva a lembrança de Eva e de seu trabalho.

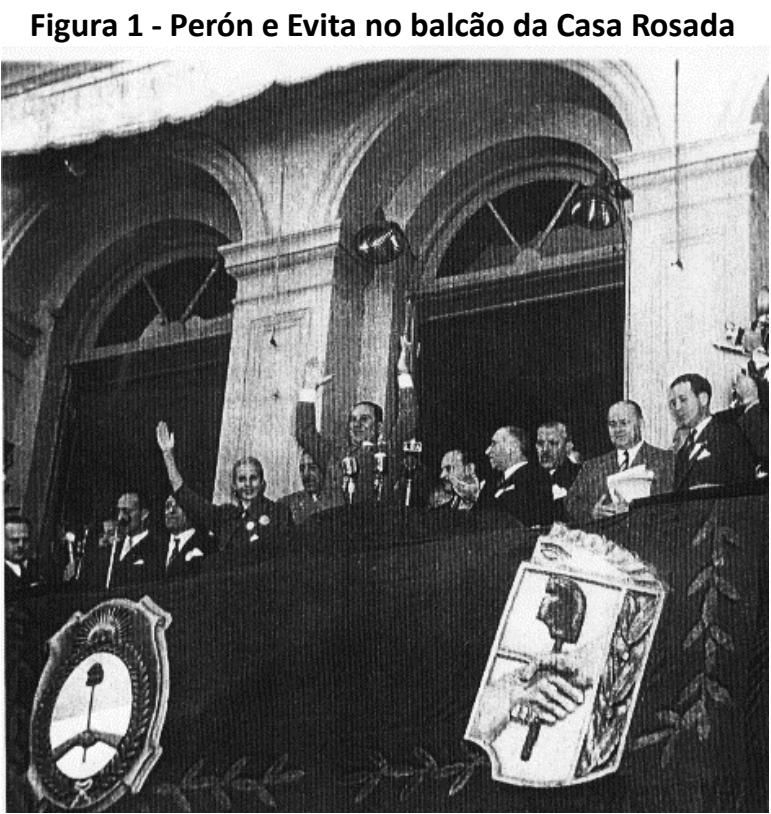

Fonte: Sanchez, 1997, p. 69.

Figura 2 - (Baradero Hoy -17de outubro de 2010).

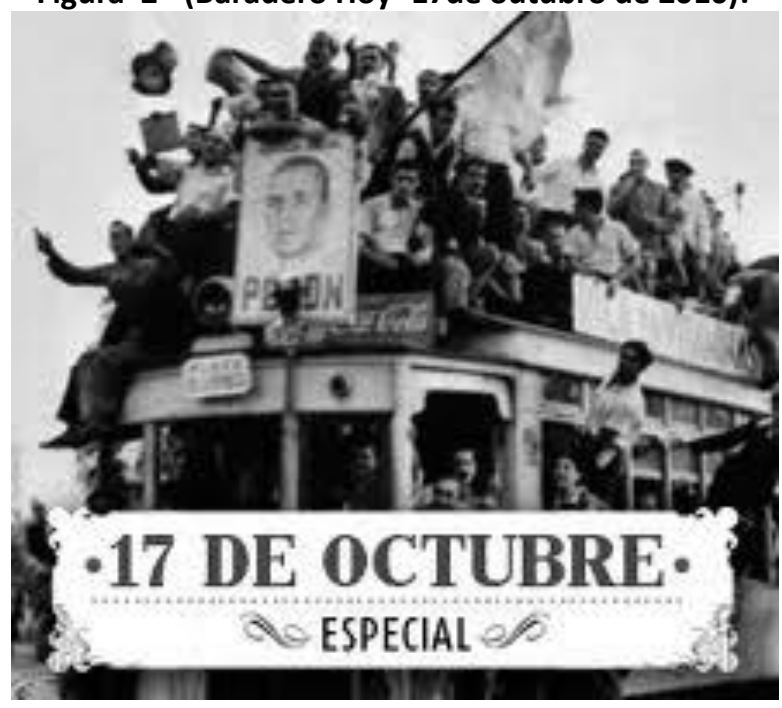

Fonte: Sanchez, 1997, p. 69.

O conteúdo simbólico para atrair as massas também foi constituído por fotos, retratos, esculturas do presidente e de sua esposa, o escudo, a bandeira. Expressões 
que caracterizaram o peronismo e suas políticas também foram as músicas, as datas celebradas pelo regime e os discursos proferidos pelos dois líderes.

A imagem dos "descamisados" constituía-se um dois símbolos de maior expressão, que reafirmou o caráter do movimento. Genericamente, esse termo significava povo, massa, porém, no imaginário peronista, afastou-se do sentido pejorativo original para ascender à posição digna de amigo do líder, sendo fundamental para o projeto governamental, pois o descamisado arregaçava as mangas e realizava esforços físicos imprescindíveis ao desenvolvimento do país.

A difusão deste ideário por meio de uma moderna propaganda ideológica e a criação de vários mecanismos de censura pelo Estado garantiu o sucesso desse amplo complexo de trabalho de doutrinamento peronista.

Ao iniciar seu mandato, Perón utilizou-se de uma série de manobras políticas para silenciar a oposição, apesar da liberdade de imprensa continuar sendo mantida pela constituição argentina. Lançando mão de pressões de ordem política e econômica, como as ações de sabotagem, corrupção, violações das leis, barreiras para importação de papel, corte dos subsídios, suspensão de direitos, o Estado foi aos poucos estabelecendo seu domínio sobre a edição de revistas e jornais.

O controle das rádios teve grande relevância na formação da memória do peronismo, pois garantiu a frequente emissão dos princípios ideológicos, tornando-se importante instrumento para consolidar sua legitimidade. Passou-se a exigir que, no mínimo, $50 \%$ da programação musical fosse nacional. Além disso, discursos do presidente e de sua esposa eram transmitidos diariamente em boletins de meia hora e, ainda, organizaram-se programas de cinco minutos, "micros", nos quais artistas famosos engrandeciam as realizações do governo, fazendo comparações com os anteriores.

Nesse cenário, as lembranças dos discursos difundidos pelo Estado revelavamnos que estes foram construídos em torno da bipolaridade e do maniqueísmo, enfatizando a luta entre Perón e seus adeptos contra os demais. Dessa forma, na memória da época, o "lugar do outro" era desprestigiado, pois a oposição não representava uma política construtiva que pudesse somar esforços para o desenvolvimento nacional, sendo definida como uma "força nociva" ao bem-estar dos argentinos.

Neste embate simbólico, projetou-se no imaginário social a contraposição entre o "moderno x o arcaico", a "moral x a corrupção", "o verdadeiro o enganoso". Uma das estratégias adotadas para reafirmar essas ideias foi manter o Partido Comunista na 
legalidade. Sua presença reforçava a Terceira Posição ${ }^{4}$, visto que era um "inimigo" sempre visível para mostrar à população as causas das dificuldades do regime, sendo os comunistas acusados pela explosão de bombas e outros atentados e, volta e meia, eram presos. Além disso, o mecanismo era usado para assinalar à oligarquia que esta alternativa seria muito mais ameaçadora a seus interesses do que a representada pelo peronismo.

A memória do povo argentino sobre os discursos exaltados de Eva Perón recorda-nos a ênfase dada aos benefícios de Perón aos trabalhadores e o repúdio aos comunistas, vistos como uma ameaça à integridade da pátria:

Ao trabalhador, há de se pagar aquilo que ele justamente merece. E o General Perón, que continua sendo o mesmo coronel que na Secretaria de Trabalho "trabalhava noite e dia pela felicidade dos descamisados", está lutando não somente para assegurar a retribuição justa a todos os operários argentinos, mas também para consolidar definitivamente suas conquistas e para que ninguém se atreva a despojá-los delas (PERÓN, 1950, p. 77).

Mesmo utilizando-se de todos esses artifícios, a alienação da maior parte da intelectualidade argentina em relação ao projeto estatal, devido ao fato de oporem-se abertamente às práticas que considerava autoritárias, não concordava com a forma pela qual o povo era integrado na política e ainda pela postura anti-intelectual de alguns setores do peronismo ${ }^{5}$, comprometeu o pleno êxito de suas políticas de caráter cultural. Assim, poucos foram os intelectuais de monta que assumiram a legenda peronista. ${ }^{6}$

Contudo, mesmo não sendo plenamente bem-sucedida, essa intervenção estatal mostrou-se eficaz no sentido de construir um imaginário social capaz de introduzir em grande parte dos indivíduos um sentimento de patriotismo. Essa parcela da população acreditou e incorporou, em suas crenças, valores cívicos, morais e éticos forjados pelo peronismo. A referência popular ao "calendário peronista" confirma tais análises. As datas mais significativas eram o 1 o de Maio, o 9 de Julho, dia da Independência, e o 17 de Outubro.

\footnotetext{
4 O líder argentino afirmava que não era aliado ao capitalismo ou ao socialismo, pois ambos estavam desconexos da realidade do país. Somente por meio da Terceira Posição, que era um modelo nacional, poderia se combater o imperialismo e as forças oligárquicas internas, tornando a nação independente.

5 Como exemplo dessa postura, pode-se citar um fato ocorrido na manifestação de 17 de Outubro de 1945, quando trabalhadores, para demonstrar sua oposição aos intelectuais que dias antes da queda de Perón tinham feito um ato contra a sua política, gritavam a frase: "Alpargatas sim, livros não".

6 Entre eles os escritores Angel Speroni, Valentín Fernando, Luis H. Velásquez, Manuek Gálvez, Maria Granata, Roberto Vagni, Leopoldo Marechal e artistas populares, como Enrique Santos Discépolo, Homero Manzi, Cátulo Castillo, Tita Martello, entre outros.
} 
As celebrações de datas cívicas possuem função de relevância na rememoração da nação, constituindo-se, também, como lugares de memória. Elas sustentam a ideologia dos grupos dominantes, ao proporcionarem uma releitura do passado, fazendo com que alguns acontecimentos sejam enaltecidos e outros caiam no esquecimento, pois não atendem aos seus propósitos.

As memórias nacionais são, portanto, "cartas mitológicas para toda uma comunidade nacional" (FENTRESS; WICHAM, 1992, p. 165) e, desta forma, visam definir essa comunida, configurando-se como "hegemônicas e totalizantes; as memórias alternativas são consideradas irrelevantes, inverídicas e até ilegítimas" (FENTRESS; WICHAM, 1992, p. 165). Em decorrência disso, observamos, no Estado Peronista, um hábil trabalho de manipulação da atividade de "lembrar e esquecer", na formação dos valores pátrios, procurando despertar o civismo nos argentinos, repudiando as memórias opostas.

A meta final do projeto nacionalista peronista era construir uma "comunidade organizada", entendida como uma "sociedade ideal", em que, por meio da "justiça social", o Estado acabaria com a exploração dos ricos sobre os pobres, garantindo aos "descamisados" uma vida digna, quando poderiam usufruir dos mesmos benefícios e gozos das classes mais abastadas, pondo fim ao conflito entre classes.

Para o estabelecimento dessa comunidade, era necessário reduzirem ao mínimo as manifestações dos grupos opositores do governo e, ainda, a estruturação de diversas corporações (sindicatos, grêmios, partido, outros) que representariam diferentes setores da sociedade, sendo o Estado o responsável pelo equilíbrio "orgânico".

Ao se afirmar que um mínimo de questionamento das políticas estatais era uma condição necessária à manutenção da harmonia na sociedade, adota-se uma postura autoritária e contraditória com um regime que foi instituído dentro das diretrizes de um estado de direito. Assim, a nação idealizada pelo peronismo afastava-se dos pressupostos defendidos pelo sistema democrático e legitimava práticas repressivas como instrumentos necessários à construção nacional. Esses princípios fundamentaram a construção da memória do regime.

\section{A CRÍTICA DA INTELECTUALIDADE ARGENTINA ÀS POLÍTICAS PERONISTAS: A LITERATURA COMO UM LUGAR POSSÍVEL DE MEMÓRIA}

Sabemos que a literatura é construção simbólica alimentada pela história. Por meio da arte literária, torna-se possível compreender percepções sobre 
acontecimentos históricos, bem como revelar posicionamentos de convergência ou manifestações de resistência a um contexto de realidade.

Gilbert Durand (2000, p. 232) afirma que as artes e as letras são refúgios tolerados do imaginário. Mostra, também, que essa complexa rede de imagens e relações de imagens que compõem o "capital pensado do homo sapiens" articula-se entre as pulsões subjetivas e as motivações objetivas que surgem no meio social. A imagem literária constitui-se, então, como uma força simbólica viva.

Em outro viés teórico, mas passível de aproximações no que se refere à concepção que aqui se pretende sobre a relação da literatura e da história, Antonio Cândido (2006) assinala ser a arte literária uma prática simbólica. Assim, na arte da palavra, podemos entrever a expressão de um imaginário da cultura, da nação, da sociedade a que se liga, de forma a compor-se como um sistema que faz interagir o estético e o histórico. Em Literatura e Sociedade, o referido autor define literatura como

[...] comunicação inter-humana, a literatura, que aparece sob esse ângulo como sistema simbólico, por meio do qual as veleidades mais profundas do indivíduo se transformam em elementos de contato entre os homens, e de interpretação das diferentes esferas da realidade (CÂNDIDO, 2006, p. 31).

Por ser prática simbólica, um discurso individual que dialoga com o coletivo, a literatura pode constituir-se como lugar de memória. Acrescenta a isso o fato de a ficção literária propiciar exercício de reflexão sobre temas extraídos de experiências vividas em sociedade e, também, promover indagações sobre a própria memória. Conforme Nora:

[...] as memórias que, por seu próprio nome, poderiam parecer lugares de memória; ou mesmo as autobiografias ou os jornais íntimos. As Mémoires d'outre-tombe, a Vie de Henry Brulard, ou o Jornal d'Amiel são lugares de memória, não porque são melhores ou maiores, mas porque eles complicam o simples exercício da memória com um jogo de interrogação sobre a própria memória. Pode-se dizer o mesmo das Memórias de homens de estado. [...] independente do valor desigual dos textos, o gênero tem suas constantes e suas especificidades: implica num saber de outras Memórias, num desdobramento do homem de escrita e do homem de ação, na identificação de um discurso individual com outro coletivo e na inserção de uma razão particular numa razão de Estado: tantos motivos que obrigam, num panorama de memória nacional, a considera-los como lugares (NORA, 1993, p. 25).

Na visão deste autor, o lugar da memória faz lembrar, ou seja, não possibilita a ação do esquecimento tão recorrente em nossa sociedade em que tudo se liquefaz. A 
escrita ficcional pode dialogar com fatos que ocorreram, ou seja, dá a ver a história e as lembranças que ela provoca.

Indissociada dos fenômenos históricos e sociais, a memória de cada indivíduo - "historiador de si mesmo" (NORA, 1993, p. 17) - dialoga com a memória social. Nesse sentido, podemos recuperar aqui a ideia de Halbwachs (1990) para quem as memórias individuais são pontos de vista sobre a memória coletiva. Assim, se a literatura revela a memória de um autor, ela também serve de lugar discursivo para interpretação da memória coletiva, ainda que possa insurgir como contra-memória, como analisaremos no conto "A casa tomada", de Júlio Cortázar.

O escritor argentino, neste texto, narra a história de dois irmãos, que sucumbem à invasão de sua casa por forças estranhas.

Sabemos que, na construção literária de um conto, o espaço é elemento de relevância. Conforme afirma Dimas (1994.), "entre as várias armadilhas virtuais de um texto, o espaço pode alcançar estatuto tão importante quanto outros componentes da narrativa, tais como foco narrativo, personagem, tempo, estrutura, etc.". (DIMAS, 1994, p. 1). Revela o autor que a forma com que projeta o espaço na obra literária é que o garante sua importância analítica. Em "A casa tomada", o espaço da casa ganha relevância a partir do título e, logo no início do conto, a casa mostra-se personalizada. Ela não está ali figurada de maneira aleatória, decorativa ou sem intencionalidade, mas guarda todo um simbolismo que aqui será analisado. Reitera o referido autor:

Um passo adiante da fotografia que imobiliza, da veracidade que se esvai ou do arrolamento que dicionariza o texto literário, estão aquelas análises que procuram penetrá-lo de maneira mais contundente, dele extraindo um significado oculto que dificilmente se mostra à primeira leitura (DIMAS, 1994, p. 10).

A casa para os dois personagens irmãos era o lugar das recordações das experiências da infância, como se lê:

Gostávamos da casa porque, além de ser espaçosa e antiga (as casas antigas de hoje sucumbem às mais vantajosas liquidações dos seus materiais), guardava as lembranças de nossos bisavós, do avô paterno, de nossos pais e de toda a nossa infância (CORTÁZAR, 2013, p. 151).

Com força e forma de personagem, a casa onde habita Irene e o protagonista é lugar onde se descreve realisticamente uma rotina. Essa descrição realista mostra-se como recurso para que a intromissão do fantástico ganhe mais força. E o uso dessa categoria estética também não é arbitrário nesse conto, como veremos adiante. 
Fazíamos a limpeza pela manhã, levantando-nos às sete horas, e, por volta das onze horas, eu deixava para Irene os últimos quartos para repassar e ia para a cozinha. $O$ almoço era ao meio-dia, sempre pontualmente; já que nada ficava por fazer, a não ser alguns pratos sujos. Gostávamos de almoçar pensando na casa profunda e silenciosa e em como conseguíamos mantê-la limpa. Às vezes chegávamos a pensar que fora ela a que não nos deixou casar (CORTÁZAR, 2013, p. 151).

Na sequência narrativa, a rotina persiste até o dia em que o personagem ouve um barulho indefinido, impreciso e surdo, caracterizando a primeira aparição do fantástico.

Andei pelo corredor até ficar de frente à porta de mogno entreaberta, e fazia a curva que levava para a cozinha quando ouvi alguma coisa na sala de jantar ou na biblioteca. O som chegava impreciso e surdo, como uma cadeira caindo no tapete ou um abafado sussurro de conversa. Também o ouvi, ao mesmo tempo ou um segundo depois, no fundo do corredor que levava daqueles quartos até a porta. Joguei-me contra a parede antes que fosse tarde demais, fechei-a de um golpe, apoiando meu corpo; felizmente a chave estava colocada do nosso lado e também passei o grande fecho para mais segurança (CORTÁZAR, 2013, p. 153).

O elemento insólito apresenta-se sem forma definida, conforme se lê: "alguma coisa" e com um som também indeterminado, "impreciso e surdo". Essa indefinição cria uma atmosfera tensa que caracteriza a presença do fantástico.

O fato de o barulho ser ouvido na sala de jantar ou na biblioteca é significativo, pois ambos são lugares representativos de que abalos serão percebidos no plano das relações sociais (sala de jantar) ou no plano das relações intelectuais motivadoras do pensar crítico (biblioteca). Sabe-se dos vários momentos autoritários na História em que livros - sobretudo de literatura - foram proibidos, desapareceram, foram queimados por representarem ameaça à instauração de alguma ideologia.

A permanência do elemento insólito provoca desdobramentos e cria um clima cada vez mais denso na narrativa, como se lê:

Entrei na cozinha, esquentei a chaleira e, quando voltei com a bandeja do chimarrão, falei para Irene:

- Tive que fechar a porta do corredor. Tomaram a parte dos fundos.

Ela deixou cair o tricô e olhou para mim com seus graves e cansados olhos.

- Tem certeza?

Assenti.

- Então - falou pegando as agulhas - teremos que viver deste lado [...] (CORTÁZAR, 2013, p. 154). 
A casa estava sendo invadida. A parte dos fundos remete a lugar pouco visível, metaforizando o lugar que guarda as emoções, a imaginação, a memória, o passado, para diferenciar da parte da frente, representativa do que se mostra ao outro, do visível, da razão, do presente.

A cozinha é lugar de criação, tendo semelhança com o tricô que cai ao chão, revelando algo estranho a ameaçar a criatividade das personagens habitantes daquele espaço que, aos poucos, passa a acomodá-las de maneira a não mais questionar.

Os primeiros dias pareceram-nos penosos, porque ambos havíamos deixado na parte tomada muitas coisas de que gostávamos.

[...]Porém também tivemos algumas vantagens. A limpeza simplificou-se tanto que, embora levantássemos bem mais tarde, às nove e meia por exemplo, antes das onze horas já estávamos de braços cruzados.[...]

Estávamos muito bem, e pouco a pouco começamos a não pensar. Pode-se viver sem pensar[...] (CORTÁZAR, 2013, p. 154).

Primeiramente, sentiram a perda material - das coisas de que gostavam - para, subsequentemente, perceberem a perda do imaterial, das ideias, dos sentimentos, dos pensamentos, das memórias. Evidencia-se um progressivo processo de alienação de si - começaram a não pensar -, da própria história e da memória.

Outros ruídos são ouvidos, cada vez mais fortes, e mais partes da casa são tomadas, até que as personagens abandonam seu lugar de vida e se lançam à rua sem oportunidade de retorno, pois as chaves são jogadas no bueiro. Os dois irmãos, Irene e o narrador, mergulhados na mesma rotina na casa em que vivem, subitamente são surpreendidos por fenômenos inusitados e desprovidos de uma lógica racional. Não vendo outra saída, abandonam o casarão. Nem o artesanato que Irene executava pode ser levado, fora abandonado na casa tomada. Levaram a história, a memória e as possibilidades de criação.

- Tomaram esta parte - falou Irene. 0 tricô pendia das suas mãos e os fios chegavam até a cancela e se perdiam embaixo da porta. Quando viu que os novelos tinham ficado do outro lado, soltou o tricô sem olhar para ele.

- Você teve tempo para pegar alguma coisa? - pergunteiIhe inutilmente.

- Não, nada.

Estávamos com a roupa do corpo.

Abandonam a casa para a rua (CORTÁZAR, 2013, p. 156).

Se tomarmos a literatura como experiência simbólica, tal como nos ensina Antonio Cândido, e a imagem da casa como elemento arquetípico do imaginário, como nos aponta Durand, faremos uma abordagem analítica de como Cortázar lê a realidade que o cerca. 
Para Bachelard (1996, p.24), a casa representa o ser interior. Trata-se de imagem que estrutura o ser humano. A casa é "um verdadeiro cosmos". Para Mircea Eliade (1975, p.35): “a casa não é um objeto", "uma máquina dentro da qual se vive"; é um universo que o homem constrói para si mesmo, imitando a criação paradigmática dos deuses. Como lugar em que se vive, em um plano coletivo, a casa pode ser compreendida como símbolo da nação, com a qual se tem sentimento de pertença.

No conto, a casa é tomada por forças estranhas, obrigando as personagens a se retirarem, sem qualquer questionamento. Ao analisarmos o contexto de produção da narrativa, teremos o ano de 1946. Inicialmente, essa narrativa foi reproduzida nos Anales de Buenos Aires pelo escritor argentino Jorge Luis Borges e, depois, publicada com outras histórias de Cortázar na obra Bestiário, lançada em 1951.

A década de 40, na Argentina, vê o surgimento de Perón na cena política. É nesse contexto que Cortázar textualiza sua percepção da realidade nacional, de maneira bastante crítica.

Antiperonista, o escritor critica a forma de governo autoritário. Essa postura era relativamente recorrente no meio intelectual, uma vez que Perón não valorizava a intelectualidade e a cultura de elite, e também não aceitava discursos em que sua posição não fosse reverenciada. Interessava-Ihe a cultura popular, nas palavras dele: "o peronismo é uma questão mais de coração que de cabeça" (FIORUCCI, 2002, p. 4).

A qualidade dos sentimentos advindos de uma experiência vivida pelo autor tanto no plano individual, como exilado do país na França, quanto no plano coletivo, da nação que experimenta um governo populista e centralizador, é metaforizada nessa narrativa cujos elementos simbólicos, sobretudo a casa, reordenam o real criativamente com o intuito de tecer séria crítica a essa forma de governo. Impregnadas pela força e pela qualidade dos afetos, as imagens desse conto questionam a memória do peronismo e revelam uma contraideologia entretecida a uma contramemória.

A fantasia, elemento substancial da literatura e atividade permanente do imaginário, é matéria-prima com a qual se produz o fantástico, categoria estética fundamental desse conto e com a qual muitos dos escritores da América Latina constituíram seus contradiscursos.

A acomodação das personagens diante da naturalização do absurdo cria no leitor esse efeito do fantástico e motiva-o a problematizar um sistema e um conjunto de valores que aparece como estável, sinalizando um movimento de resistência.

Para David Roas (p.21), "um dos objetivos do fantástico atual é oferecer ao leitor histórias que o façam experimentar uma indescritível inquietação ante a falta de 
sentido revelada e percebida no seu contexto real e cotidiano". Nesse conto, o uso do fantástico faz reverberar o tom de ironia que o autor deseja imprimir à narrativa.

O momento histórico vivido por Cortázar reflete-se na criação de um imaginário da nação que denuncia, de maneira velada e cifrada tão característica da arte literária, uma insatisfação provocada por um estranhamento. A intromissão na narrativa de um elemento insólito - a progressiva tomada da casa -, que anuncia a presença do fantástico, serve de recurso para provocar estranhamento no leitor sobre uma situação que merece ser questionada e recusada.

Cabe relembrar mais uma vez Antonio Cândido (1997, p. 34) com a ideia de que a obra é "uma realidade própria" e, como realidade própria, exprime uma visão de mundo, uma posição diante de certos temas por meio dos quais se entrevê "o espírito e a sociedade". Compreender isso poderá abrir caminhos para entender o momento histórico e ideológico, a cultura, que se compõe como realidade existencial em qualquer tempo. Ademais, vale ressaltar o valor da palavra artística como vetor de linguagem para a efetivação dessa vontade expressiva.

Uma obra é uma realidade autônoma, cujo valor está na fórmula que obteve para plasmar elementos não-literários: impressões, paixões, idéias, fatos, acontecimentos, que são a matéria-prima do criador. A sua importância quase nunca é devida à circunstância de exprimir um aspecto da realidade, social ou individual, mas a maneira por que o faz. No limite, o elemento decisivo é o que permite compreendê-la e apreciá-la, mesmo que não soubéssemos onde, quando, por quem foi escrita. Esta autonomia depende, antes de tudo, da eloqüência do sentimento, penetração analítica, força de observação, disposição das palavras, seleção e invenção das imagens; do jogo e elementos expressivos, cuja síntese constitui a sua fisionomia, deixando longe os pontos de partida nãoliterários (CANDIDO, 1997, p .33).

No mesmo sentido, concordamos com Nelly Novaes Coelho (1985, p. 220), ao expressar que o valor literário de uma obra não pode ser mensurado por sua pertença a uma ou outra tendência literária, mas "pela consciência do fazer literário revelado por sua matéria literária, seu corpo verbal; e, também, pela adequação de tal matéria às forças renovadoras mais atuantes em seu momento de produção". Vale, aqui, assinalar a ideia de que o contexto ideológico por si não confere valor de renovação à obra se esta não se transfigurar em arte, ou seja, é necessário enlaçar o ideológico e o estético. A literatura configura-se como fenômeno de linguagem, pois é pela força das palavras em seus arranjos criativos que ela se faz reconhecer.

A incursão pela "casa tomada", como território literário, corresponde a uma reflexão sobre modos de ver, sentir e pensar constelados no cerne do imaginário desse 
autor, capaz de traduzir sensibilidades da época. No conto de Cortázar, nenhum efeito de sentido é criado aleatoriamente, mas a intenção expressiva preside. Sugere o autor uma visão singular, em seu projeto estético e político, ao construir na imagem da casa a metáfora de uma nação. Operando com aquilo que sintoniza como "afinidade eletiva", ou seja, com aquilo que se projeta como eleição da sensibilidade para seu projeto literário, captura a realidade à sua maneira e a transcria de maneira a fazer pensar sobre o sentido da história pelo sentido da estória (ou mesmo na ausência de sentido), tanto na direção do passado quanto na do futuro.

Vale assinalar que a literatura tem se revelado como lugar de memória, respondendo à necessidade do indivíduo contemporâneo em deixar marcas de sua história a partir das quais se torna possível não apenas repensar sentimentos e relações, mas também reinventar o vivido.

\section{CONSIDERAÇÕES FINAIS}

Urge, nos tempos atuais, criar laços e caminhos interpretativos entre as diversas áreas do conhecimento para que se possa ter uma compreensão mais sensível sobre a realidade complexa que nos abarca. Se antes a história e a literatura eram campos do saber que se mostravam aparentemente incomunicáveis, hoje temos a clareza de que, ao menos, pelo fio da memória, elas podem dividir fronteiras para somar conhecimento.

Entre os tantos lugares de memória, a literatura como campo de cultivo do simbólico contribui sensivelmente para compreender aspectos da reconstrução da experiência vivida.

É Nora quem nos alerta para a ideia de que "todos os corpos constituídos, intelectuais ou não, sábios ou não, apesar das etnias e das minorias sociais, sentem a necessidade de ir à busca de sua própria constituição, de encontrar suas origens" (NORA, 1993, p. 17).

Faz-se papel dos pesquisadores e intelectuais mobilizar reflexões e ações para que a memória social seja democratizada e possa servir tanto ao passado quanto ao futuro para o desígnio da libertação dos homens.

Neste sentido, nosso estudo sobre a construção da memória do peronismo, entre 1946 a 1955 e as críticas a esse processo expressas na obra de Cortázar contribuem para desmistificar o imaginário social criado em torno deste movimento político que ainda hoje tem forte impacto na cultura política latino-americana. Assim, em uma perspectiva interdisciplinar, buscou-se analisar a criação de seus mitos, símbolos e comemorações como lugares de memória para a legitimação do regime, 
como também a criação de imaginários de refúgio à ordem imposta por meio da literatura.

\section{REFERÊNCIAS}

BACHELARD,Gaston. A poética do espaço. Coleção os grandes pensadores. São Paulo: Abril Cultural, 1978.

CANDIDO, Antonio. Formação da literatura brasileira: v.1. 8. ed. Belo Horizonte; Rio de Janeiro: Itaitaia, 1997.

. Literatura e sociedade. Rio de Janeiro: Ouro sobre o azul, 2006.

CIRIA, Aberto. Política y cultura: la Argentina Peronista, 1946-1955. Buenos Aires: De La Flor, 1983.

COELHO, Nelly Novaes. Panorama histórico da literatura infantil/juvenil. São Paulo: Quíron, 1985.

CORTÁZAR, Julio. A casa tomada. In: Antologia da literatura fantástica. São Paulo: Cosac Naify, 2013.

DIMAS, Antonio. Espaço e romance. São Paulo: Ática, 1994.

DURAND, Gilbert. Campos do imaginário. Lisboa: Instituto Piaget, 2000.

ELIADE, Mircea. Imagens e símbolos: ensaio sobre o simbolismo mágico-religioso. São Paulo: Martins Fontes,1975.

FENTRESS, James; WICKHAM, Chris. Memória social: perspectivas sobre o passado. Lisboa: Teorema, 1992.

FIORUCCI, Flavia. Los marginados de la Revolución: los intelectuales peronistas $(1945,1955)$. In: Congresso Brasileiro de Hispanistas, 2, 2002. Anais.... 2002.

HALBWACHS, Maurice. A memória coletiva. Rio de Janeiro: Vertice, 1990.

TODO sobre el 17 de octubre de 1945. In: Baradero Hoy. Disponível em: <http://www. baraderohoy.com/2010/10/17/todo-sobre-el-17-de-octubre-de-1945/>. Acesso em:10 fev. 2015.

LE GOFF, Jacques. História e memória. São Paulo: Unicamp, 2003. 
NEIBURG, Federico. Os intelectuais e a invenção do peronismo. São Paulo: Edusp, 1997. NORA, Pierre. Entre memória e história: a problemática dos lugares. In: Projeto História. São Paulo, dez 1993.

_. Les lieux de mémoire. I La République. Paris: Gallimard, 1984. p. XVIII-XLII.

PERÓN, Eva. La palabra y el pensamiento de Eva Perón. Buenos Aires: Presidencia. Subsecretaria de Informaciones, 1950.

PLOTKIN, Mariano. Rituales políticos, imágenes y carisma: la celebración del 17 de Octubre y el imaginário peronista 1945-1951. In: TORRE, J.C. (comp.). El 17 de Octubre de 1945. Buenos Aires: Ariel, 1995.

ROAS, David. A ameaça do fantástico. São Paulo: Unesp, 2014.

SANTOS, Raquel Paz dos. Nova Argentina: imaginário de uma nação. Rio de Janeiro: UNIRIO, 2001.

SANCHEZ, Matilde. et. al. Evita: imagens de uma paixão. São Paulo: Melhoramentos, 1997. 